Weale is somewhat atypical. In this he deals with photoreceptors with emphasis on "directional" aspects in a setting which is chiefly mammalian. Thirteen absorbing pages are devoted to the Stiles-Crawford effect.

It is characteristic of the whole text that references are given fully, but not in profusion; they are representative and rewarding.

Early in the book there is an extensive consideration of sources of radiation and the means by which flux may be modified and conveyed. The relative merits of lamps are summarized with appropriate stress on the practical importance of simulated "daylight". Much may be gained by most readers from the survey of beam splitters, self-made pellicles and the forms of lenses. A little enterprise with symbols suffers from inconsistency. More might be made of typical systems of condensing lenses and of achromatic projection lenses. The details about filters of many types and about monochromators comprise a model chapter. In such a book there is some difficulty over the decision to avoid listing suppliers of apparatus and components; such information has almost entirely been left out. Useful tables amplify certain chapters, especially where photometric matters are concerned. Practical standards, calibration devices, shutters and the control of flashes of light have been covered.

The last thirty pages of the book are devoted to a series of typical examples. Each item, from baffled diffusion system to retinal image stabilizer, is a gem. The Helm. holtz colorimeter is outlined, together with that classical counterpart, the Wright colorimeter. Attempts to provide for the stimulation of single cells are described.

ROBERT FLETCHER

\section{INFRARED TECHNIQUES}

\section{Infra-red Spectra and Structure of Organic Long-chain Polymers}

By Arthur Elliott. Pp. viii +119. (Arnold: London, January 1969.) 358.

DR EulotT has produced a somewhat abridged but authoritative and informative monograph on the application of infrared techniques in the study of polymer and biological molecules. The emphasis is, however, clearly in the former field. It has been divided into five chapters which deal with the general principles of the method, the experimental techniques, vibrations in chain molecules, the application of polarized radiation and a final chapter of special topics in the spectroscopy of polymers.

The first chapter deals with the fundamentals of infrared absorption in atoms and molecules generally, and particularly the symmetry and quantum conditions for such absorptions to take place. In the chapter on experimental methods, which I suggest might have been expanded, the author pays little tribute to his own contributions in this field, but in particular the section (G) procedure is very clearly outlined. In chapter three the transformation from the study of single vibrations to those found in polymer chains is somewhat curtailed, and, although this work is correctly described, it probably suffers somewhat from the terseness of style which has been mentioned. The chapter on the use of polarized radiation and polymer orientation is excellent and clearly shows Elliott's own contributions in this field. In the final chapter, which deals with special problems in polymer spectroscopy, the examples are well chosen and clearly illustrated.

The work will be of great value as an introduction to infrared spectroscopy to all serious students and research workers and is to be recommended as such. It might have been of greater value had it not been so clearly abridged in its presentation.

\section{SOLVENT CHEMISTRY}

Nonaqueous Solvents

By R. A. Zingaro. (Topics in Modern Chemistry.) Pp. vi+106. (Heath: Lexington, Mass.; Harrap: London, January 1969.) $1886 d$.

THIs book is another member of the series "Topics in Modern Chemistry" and presents the undergraduate reader with an introduction to non-aqueous solvent chemistry.

After an introductory chapter dealing with general ideas of solvent behaviour and a further chapter treating concepts of acid-base reactions in non-aqueous media, several solvents are considered individually. The author has chosen systems which have proved either of industrial importance-anhydrous hydrogen fluoride and liquid sulphur dioxide; or of great preparative use in organic and inorganic chemistry-liquid ammonia.

In the chapter dealing with liquid sulphur dioxide, the author highlights the dilemma of whether the solvent is coordinating or self-ionizing. It is perhaps unfortunate that, throughout the book, the former model receives much briefer attention than does the latter. It is unusual in a text on this topic to find mention of solvent extraction techniques. In this volume, however, the penultimate chapter is devoted to this aspect and, once again, the chosen examples are of industrial importance.

The final chapter deals with, potentially, the largest class of solvents, the fused salt systems. A number of experimental techniques is described and some results of spectroseopic studies are discussed. In an introductory text, ligand field spectra of transition metal complexes isolated from fused. salts can receive only a naïve treatment, but the use of " $g$ " and " $u$ " in the description of tetrahedral systems is unfortunate. The problems and suggestions for further reading included throughout the book, however, should turn the interested reader to the more advanced texts which are available. These can provide that depth of understanding which this short introductory volume does not claim to do.

\section{J. A. Salthouse}

\section{PAY AND PRODUCTIVITY}

\section{A Century of Pay}

The Course of Pay and Production in France, Germany, Sweden, the United Kingdom, and the United States of America, 1860-1960. By E. H. Phelps Brown and Margaret H. Brown. Pp. 476. (Macmillan: London; St Martin's Press: New York, 1968.) $105 s$.

THE authors have assembled a vast amount of informa. tion on wages, production, capital and other related economic indices for five countries over the past century. Their main concern is with trends in wages and the share of pay in income, and they find that over the period as a whole real wages rose by a factor of 4 or more in France, Germany and the United Kingdom, and by about 6.5 in Sweden and the United States. Advances in productivity were found to be by far the most important determinant of the increases in real earnings, while shifts in the share of income going to the worker and changes in the terms on which he exchanged his own product for units of consumption were of minor importance and sometimes worked in an adverse direction. In turn, the upward trend in productivity can be attributed mainly to advances along the technical front.

This brief summary of the main findings scarcely does justice to a book into which very many man-hours of work have been sunk. The range of data presented is quite formidable and the authors analyse carefully a wide variety of factors which influence the movement of wages. 